$\mathbb{T}$ periodica polytechnica

Civil Engineering

$58 / 4(2014) 355+370$

doi: $10.3311 /$ PPci.2101

http://periodicapolytechnica.org/ci

Creative Commons Attribution (1)

RESEARCH ARTICLE

\section{ANALYSES OF MULTI-EDGE FOOTINGS RESTED ON LOOSE AND DENSE SAND}

\author{
Burakbey Davarci / Murat Ornek / Yakup Turedi
}

Received 2013-04-30, revised 2013-11-12, accepted 2014-02-21

\begin{abstract}
Shallow footings are generally designed as square, rectangular, strip, circular or ring in geotechnical engineering. In some cases, different shallow footing geometries (irregular footing geometries) also can be selected because of the static, architectural and economical reasons. Multi-edge shallow footings are irregular shaped footings having the number of the edges and sides greater than four. They are used to transmit the loads from the irregular shaped structures to the underlying soils safely and economically. The study presented herein describes the use of artificial neural networks (ANNS) and multi-linear regression model (MLR) for prediction of ultimate loads of multi-edge shallow footings. The data used in running of network models have been obtained from extensive series of laboratory model tests. The parameters investigated are the footing width, the footing length and the density of sand soil. A total of fifty tests were performed using the parameters of the footing geometry $(\mathrm{H},+$, $T$ and square shaped), the footing size and the soil type (loose sand, dense sand) on the bearing capacity characteristics. The results of the experimental study proved that the soil density and the footing size had considerable effects on the load of and the ANN model serves as simple and reliable tool for predicting the behavior of the multi-edge footings.
\end{abstract}

\section{Keywords}

model test $\cdot$ multi-edge footing $\cdot$ bearing capacity $\cdot$ sand

\section{Burakbey Davarci}

Mustafa Kemal University, Civil Engineering Department, 1200 Iskenderun / Hatay, Turkey

e-mail: burakbey_80@hotmail.com

\section{Murat Ornek}

Mustafa Kemal University, Civil Engineering Department, 1200 Iskenderun / Hatay, Turkey

e-mail:mornek@mku.edu.tr

\section{Yakup Turedi}

Mustafa Kemal University, Civil Engineering Department, 1200 Iskenderun / Hatay, Turkey

e-mail: yturedi@mku.edu.tr

\section{Introduction}

Estimation of the bearing capacity and settlement of shallow footings is an important task in geotechnical engineering. Proper estimation results in economical and reasonable footing design. It is known that many investigations have been carried out on strip, square, circular and ring footings to evaluate their bearing capacities. However, the bearing capacity and settlement of shallow footings with unordinary geometries has been less investigated.In some cases, different shallow footing geometries (irregular footing geometries) also can be selected because of the static, architectural and economical reasons. For example, some machine footings may be categorized unordinary since they may have holes to provide access to internal parts of machine. The bearing capacity of such footings may not be calculated using traditional closed-form equations. Another example can be given in offshore engineering where structures have to sustain large lateral loads and moments produced by environmental conditions, skirt footings may be used for bearing capacity improvement. This is achieved by adding vertical plates beneath the foundation raft. These skirts are expected to constrain the soil between them and thereby improve foundation performance equivalent to that a foundation embedded to the depth of the skirt tips. There are different investigations to explain behavior of skirted-foundations [3, 4, 37, 40]. Shell-footings can be assumed as another type of footings. Shells in modern footings engineering however are still newcomer although ceiling-shells have been known since long ago. However, some major differences like buckling, weight loads and thickness, distinguishes analysis and design of these two shells from each other. Shell footings are economical and have greater load carrying capacity compared with flat shallow footings. Shell footings are constructed in various geometries such as conical, pyramidal, hyper and spherical shapes [26]. Ghazavi and Hadiani [13] carried out experimental laboratory tests on model footings with various geometries. In their study, they estimated the bearing capacity of multi-edge footings using an empirical approach based on experimental data. Cross-shape, $\mathrm{H}$-shape and T-shape footings have been modeled and loaded until the samples fail. Ghazavi and Hadiani [13] concluded that multi-edge foundations may 
have better performance than a square-shape foundation with the same width. Moreover some empirical expressions were presented to show correlation between these footings and square footings of the same width. Ghazavi and Mokhtari [14] present a numerical investigation on the behavior of irregular shallow footings for observing the displacement field under the footings. For this purpose, FLAC 3D software has been used for their analysis. They concluded that there is not a distinguishing difference between bearing capacity of multi-edge foundations and square foundation when they are of the same area.

Artificial neural networks are a form of artificial intelligence; try to simulate the behaviour of the human brain and nervous system. They have the ability to relate between the input data and corresponding output data which can be defined depending on single or multiple parameters for solving a linear or nonlinear problem. In the recent years, the use of artificial neural networks has increased in geotechnical engineering. Artificial neural networks have been applied in many geotechnical engineering problems successfully such as pile capacity, settlement of foundations, soil properties and behaviour, liquefaction, earth retaining structures, slope stability, tunnels and underground openings. Comprehensive information about the applications mentioned above can be found in the literature [2, 6, 7, 12, 20, 21, 24, 25, 27, 30, 31, 33, 34, 39].

The study presented herein describes the use of artificial neural networks (ANNs) and multi-linear regression model (MLR) for prediction of bearing capacity of multi-edge shallow footings rested on both loose and dense sand soils. The data used in running of network models have been obtained from extensive series of laboratory model tests. A total of fifty tests were performed using the parameters of the footing geometry $(\mathrm{H},+$, $\mathrm{T}$ and square shaped), the footing size and the soil type (loose sand, dense sand) on the bearing capacity characteristics. The findings will help in better understanding of the multi-edge shallow footings design with different soil density and with different footing geometry and size. It is expected that the information presented in this study will provide a contribution to the literature results and will be an alternative source for design and applications for geotechnical engineers. This will result in decrease in cost of construction and save simplicity and time for the engineer, the contractor and the owner of construction.

\section{Geometric parameters investigated}

Fig. 1 shows the geometry and loading system of the model multi-edge footings considered in this investigation. The loadings were conducted with four different shaped and 25 different sized footings. The geometries of the footings are given in Table 1. Similar model test configurations have been performed both for loose and dense sands.

\section{Test equipment and materials}

The experimental program was carried out using the facility in the Geotechnical Laboratory of the Civil Engineering De- partment of the Mustafa Kemal University, Iskenderun, Hatay, Turkey. The facility and a typical model are shown in Fig.2 and Fig. 3 .

\subsection{Test Tank}

Tests were conducted in a steel tank with dimensions $0.7 \mathrm{~m}$ (length) $0.5 \mathrm{~m}$ (width) $0.5 \mathrm{~m}$ (depth). The bottom and vertical edges of the tank were stiffened using angle sections to avoid lateral yielding during soil placement and loading of the model footing. Two side walls of the tank consist of $10 \mathrm{~mm}$-thick glass plate and the other sides consist of $3 \mathrm{~mm}$-steel plate. Therefore the inside walls of the tank were enough smooth to minimize side friction. The boundary distances were greater than the footing length, width and depth, and during the tests it was observed that the extent of failure zones was not more than the footing geometry, the frictional effect was insignificant to affect the results of model tests. Static vertical loads were applied to the model foundations by an electrically-operated mechanical jack attached to a loading frame located above the tank. Load and displacement measurements were taken using a pressure cell and two LVTD's installed between the jack and the model footing.

\subsection{Model Footings}

Loading tests were carried out on four different model rigid foundations fabricated from mild steel. All models had thicknesses of $10 \mathrm{~mm}$. Typical model geometries of the footings are shown in Fig. 1, above.

\subsection{Test Medium}

Uniform, clean, fine sand obtained from the Ceyhan River bed was used for the model tests. Laboratory tests were conducted on representative sand samples for gradation, specific gravity, maximum and minimum densities and strength parameters. These properties are summarized in Table 2. The particle size distribution of this sand is shown in Fig. 4. The model tests were conducted on loose sand and dense sand conditions. The angle of shearing resistances of the loose and dense sand $\left(D_{r}=75 \%\right)$ at dry unit weights of $16.65 \mathrm{kN} / \mathrm{m}^{3}$ and $17.11 \mathrm{kN} / \mathrm{m}^{3}$ for normal pressures of 50, 100 and $200 \mathrm{kPa}$ were determined by direct-shear testing. The measured average peak friction angles were $36^{\circ}$ and $42^{\circ}$ for loose and dense sands, respectively.

\section{Experimental procedures}

\subsection{Preparation of the Sand Bed}

The sand bed was prepared up to the base level of the model footings in layers $50 \mathrm{~mm}$ thick. Each layer was compacted by a hand-held vibratory compactor. After the compaction of each sand layer, the next lift height was controlled using scaled lines on the glass plates of the test pit. After bed preparation, the sand was carefully leveled in the areas directly beneath the footing. This was to ensure that the model footing had full contact with the sand and that the load applied to the foundation was vertical (normal). The model footing tests were performed with the 

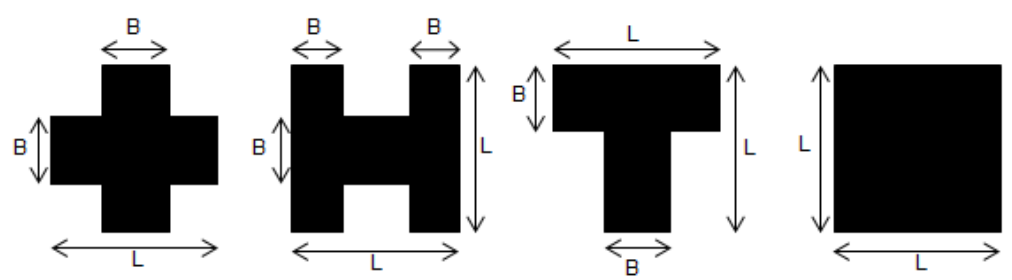

(a)

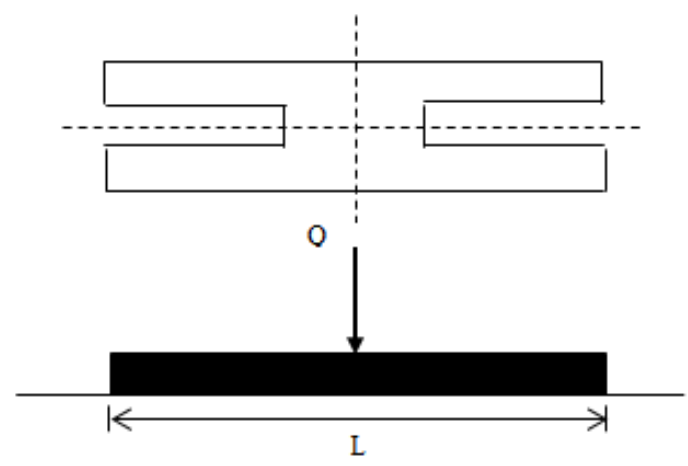

(b)

Fig. 1. Strip footings: (a) plan view; (b) elevation

Tab. 1. The geometries of the footings used in the tests

\begin{tabular}{ccc}
\hline Footing Type & No of Footing & B x L [cm] \\
\hline + Shaped & 7 & $\begin{array}{c}3 \times 10 ; 4 \times 12.5 ; 3 \times 15 ; 4 \times 15 ; 5 \times 15 ; \\
6 \times 15 ; 7 \times 15\end{array}$ \\
\hline H Shaped & 5 & $3 \times 10 ; 4 \times 12.5 ; 4 \times 15 ; 5 \times 15 ; 6 \times 15$ \\
\hline \multirow{2}{*}{ T Shaped } & 7 & $3 \times 10 ; 4 \times 12.5 ; 3 \times 15 ; 4 \times 15 ; 5 \times 15 ;$ \\
& & $6 \times 15 ; 7 \times 15$ \\
\hline \multirow{2}{*}{ Square Shaped } & \multirow{2}{*}{6} & $5 \times 5 ; 10 \times 10 ; 15 \times 15 ; 20 \times 20 ;$ \\
& & $25 \times 25 ; 30 \times 30$ \\
\hline
\end{tabular}

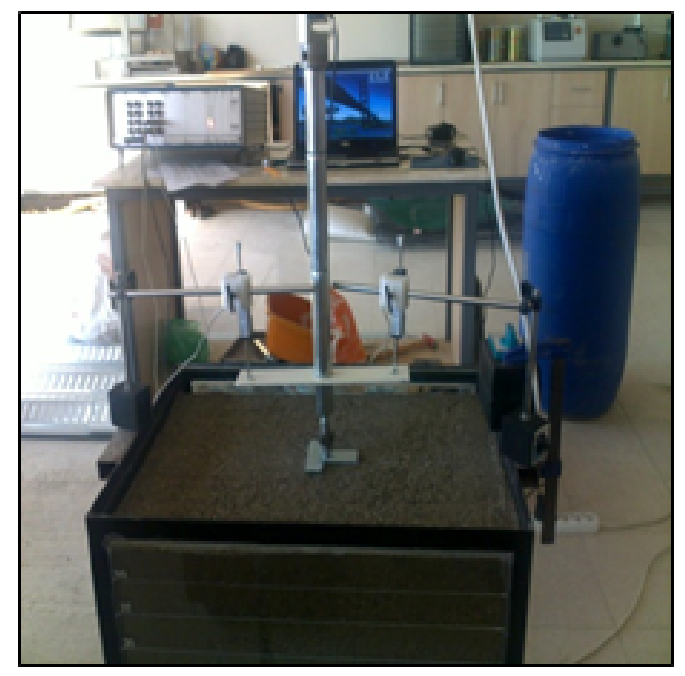

(a)

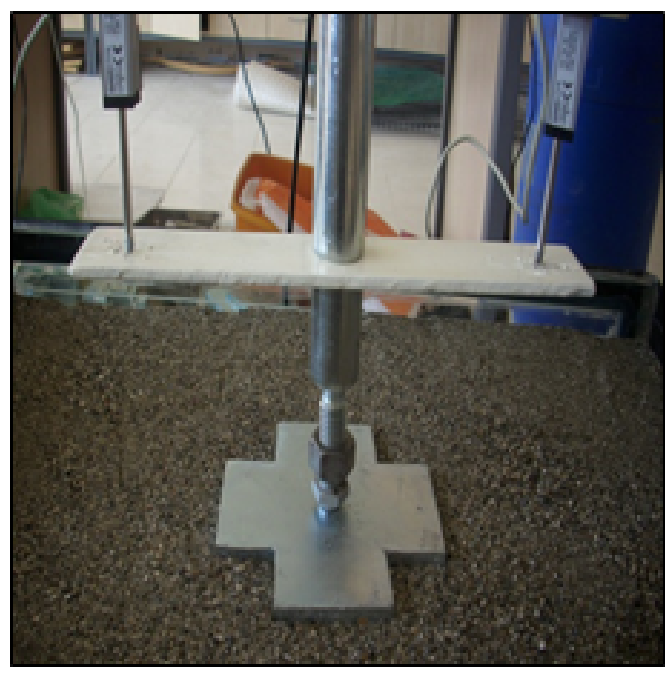

(b)

Fig. 2. Test setup: (a) overview, (b) footing 


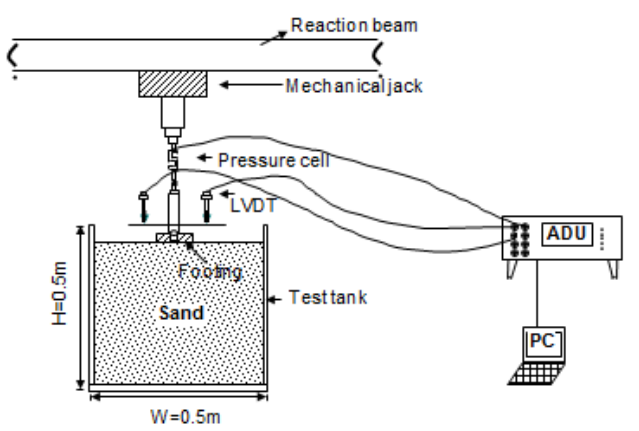

(a)

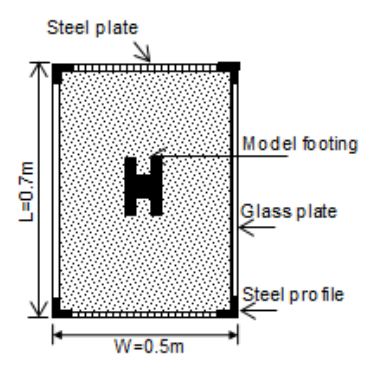

(b)

Fig. 3. General layout of apparatus for model test: (a) elevation; (b) plan view

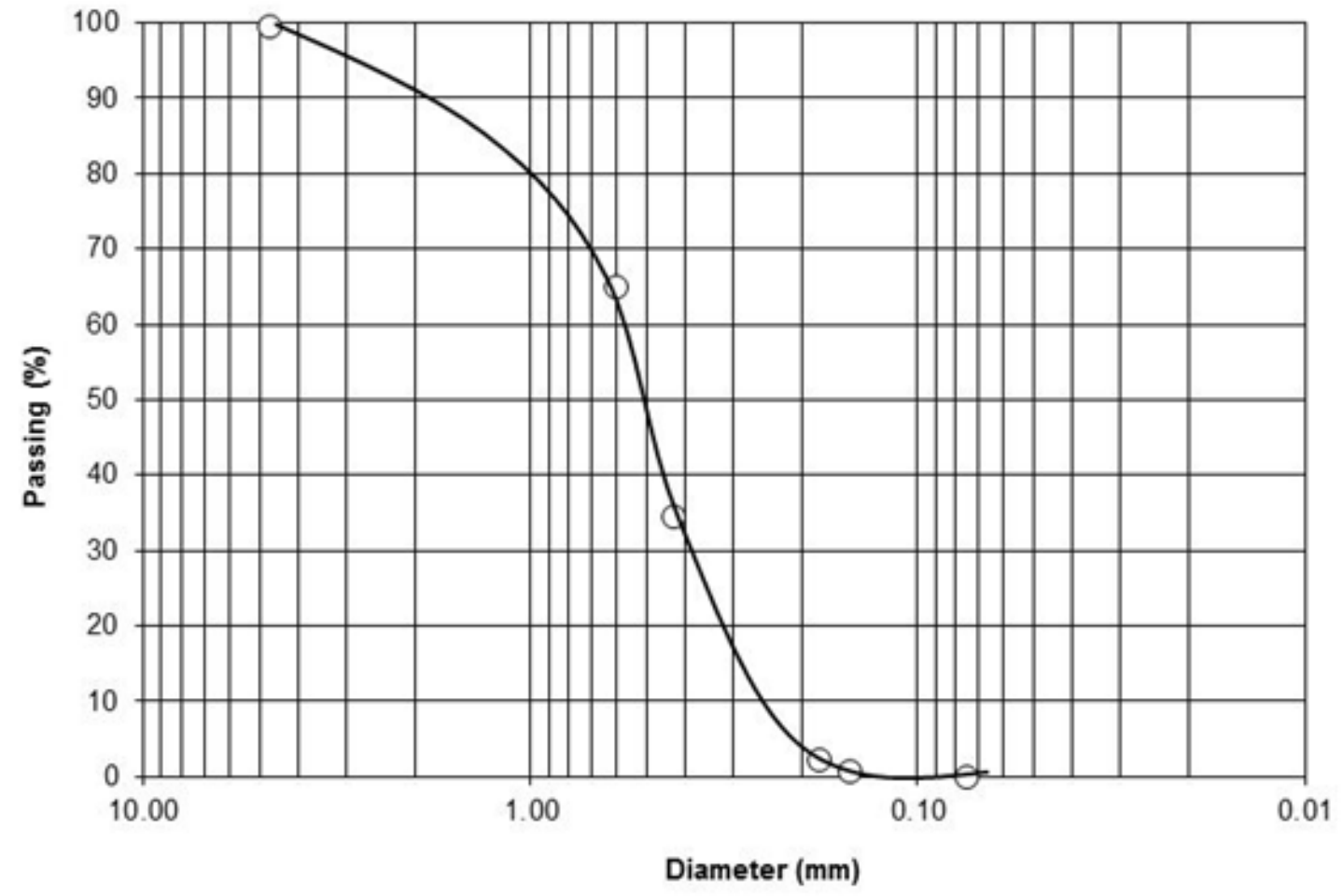

Fig. 4. Particle size distribution of test sand 
Tab. 2. Properties of sand beds

\begin{tabular}{|c|c|}
\hline Property & Value \\
\hline Coarse sand fraction (\%) & 0.00 \\
\hline Medium sand fraction (\%) & 65.00 \\
\hline Fine sand fraction (\%) & 35.00 \\
\hline$D_{10}(\mathrm{~mm})$ & 0.13 \\
\hline$D_{30}(\mathrm{~mm})$ & 0.28 \\
\hline$D_{60}(\mathrm{~mm})$ & 0.58 \\
\hline Uniformity coefficient, $C_{u}$ & 4.46 \\
\hline Coefficient of curvature, $C_{c}$ & 1.04 \\
\hline Specific gravity & 2.75 \\
\hline Maximum dry unit weight $\left(\mathrm{kN} / \mathrm{m}^{3}\right)$ & 17.11 \\
\hline Minimum dry unit weight $\left(\mathrm{kN} / \mathrm{m}^{3}\right)$ & 15.44 \\
\hline \multicolumn{2}{|l|}{ Dry unit weights during model tests $\left(\mathrm{kN} / \mathrm{m}^{3}\right)$} \\
\hline Loose Sand & 15.44 \\
\hline Dense Sand $\left(D_{r}=75 \%\right)$ & 16.65 \\
\hline Cohesion, c (kPa) & 0.00 \\
\hline \multicolumn{2}{|l|}{ The angle of shearing resistance of the sand, $\varphi$ (degrees) } \\
\hline Loose sand & 36.00 \\
\hline Dense Sand & 42.00 \\
\hline Classification (USCS) & SP \\
\hline
\end{tabular}

sand at unit weights of $15.44 \mathrm{kN} / \mathrm{m}^{3}$ and $16.65 \mathrm{kN} / \mathrm{m}^{3}$. To maintain the consistency of in-place density throughout the test pit, the same compactive effort was applied on each layer. The difference in densities measured was found to be less than $1 \%$. In all tests the minimum depth of sand below the base of the model was $0.45 \mathrm{~m}$. After completion of each test, the test pit was excavated to a depth of $1.5 \mathrm{~B}$ beneath the footing. This depth was chosen since the stress distribution calculated from the computer program [5] dissipates to effectively zero at a depth of about $1.5 \mathrm{~B}$ below the footing.

\subsection{Model Tests}

The model footing was placed on the surface of the sand bed at predetermined locations in the test pit. Vertical compressive load was gradually applied to the model footing by means of a mechanical jack supported against a reaction beam. Then the load was measured using a calibrated pressure cell. A ball bearing was positioned between the proving ring and the footing model to ensure that no extraneous moment was applied to the footing. Constant load increment was maintained until the footing settlement had stabilised. Settlements of the footing were measured using calibrated two LVDT's (Novotechnik TYP TR 50) placed on either side of the footing as shown in Fig. 2. For each test, load-settlement readings were recorded by a sixteenchannel data logger unit (MM700 series Autonomous Data Acquisition Unit) and converted to produce values of settlement at ground level and load using Geotechnical Software-DS7 on a PC. The tests were continued until the applied vertical load clearly reduced or a considerable settlement of the footing resulted from a relatively small increase of vertical load. At the end of each test, the sand was carefully excavated.

In this study, four series of tests were conducted on the model footings. The details of the tests are given in Table 3

Tab. 3. Details of model tests

\begin{tabular}{|c|c|c|c|}
\hline Test Series & Footing Type & Soil Condition & Number of Test \\
\hline \multirow{2}{*}{ I } & \multirow{2}{*}{ + Shaped } & Loose & 7 \\
\hline & & Dense & 7 \\
\hline \multirow{2}{*}{ II } & \multirow{2}{*}{ H Shaped } & Loose & 5 \\
\hline & & Dense & 5 \\
\hline \multirow{2}{*}{ III } & \multirow{2}{*}{ T Shaped } & Loose & 7 \\
\hline & & Dense & 7 \\
\hline \multirow{2}{*}{ IV } & \multirow{2}{*}{ Square Shaped } & Loose & 6 \\
\hline & & Dense & 6 \\
\hline
\end{tabular}

\section{Results and discussion}

\subsection{Interpretation of Test Results}

Generally, the type of failure in sandy soil was observed as general shear failure. In this type of failure a peak value of $Q_{u}$ is clearly defined in the curve of settlement against load (Fig. 5).

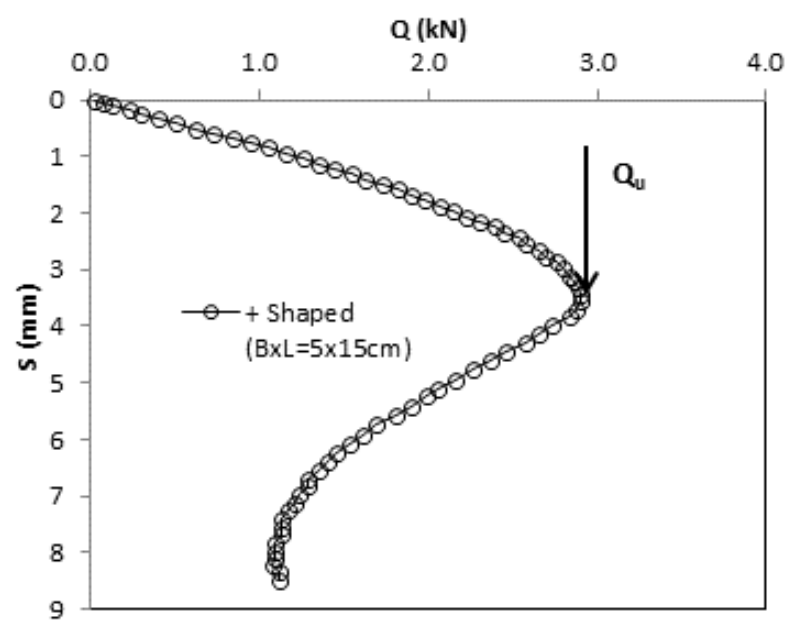

Fig. 5. General shear failure

\section{Test Series I: Tests on + Shaped Footings}

The effects of footing size and soil density on + shaped footings were investigated in Test Series I. A total of 14 tests have been carried out using seven different footing sizes reported in Table 1. The load-settlement curves shown in Fig. 6 indicated that the loads increase with an increase in footing size both for loose and dense sand cases. Similarly, for a constant settlement value, the loads of dense sand are greater than that of loose sand. The formation in failure of footings occur symmetrical failure surfaces at both sides of the footings. The heave zones obtained during the tests are symmetrical both for loose and dense sands. For the loose sands at the failure stages, the loads and settlements remain almost constant. On the other hand, for the dense sands at the failure stages, the loads start to decrease while settlements increase.

The relationships between ultimate load $\left(Q_{u}\right)$ - ultimate bearing capacity $\left(q_{u}\right)$ and footing area $(\mathrm{A})$ are shown in Fig. 7 


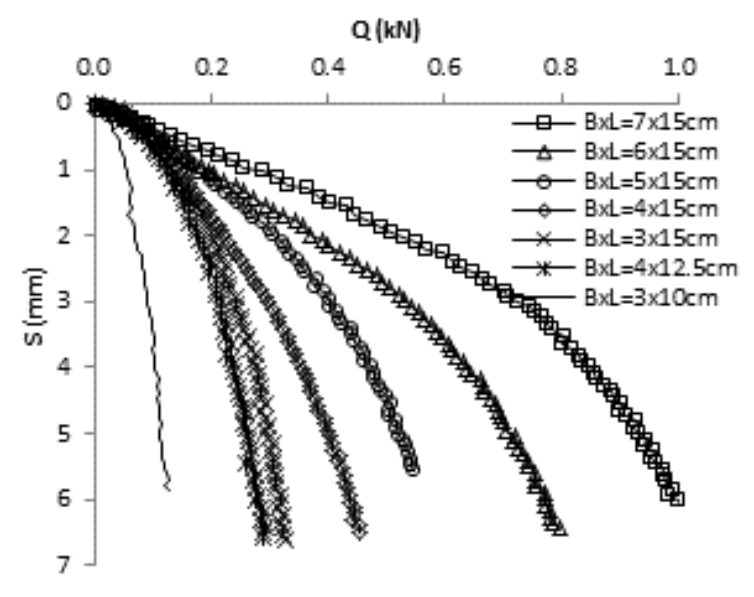

(a)

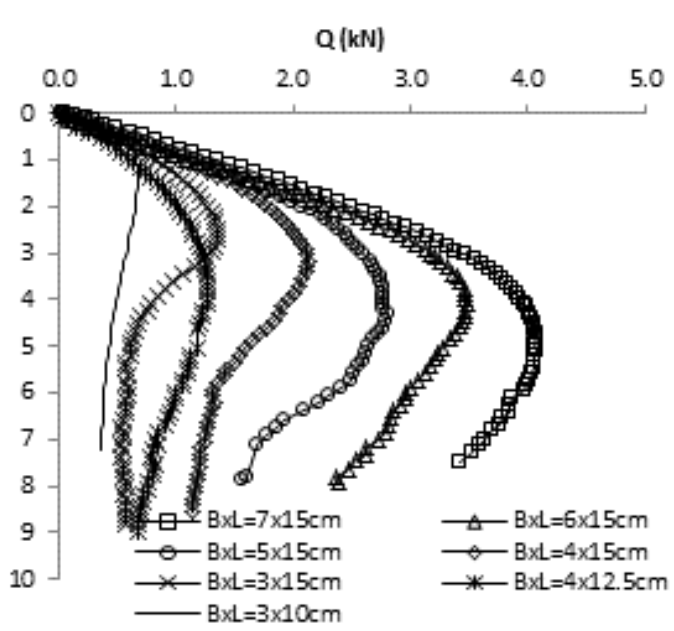

(b)

Fig. 6. Load settlement curves of + shaped footings for a) loose sand and b) dense sand

As seen that the $Q_{u}$ and $q_{u}$ values increase with an increase in footing area in both loose and dense sands. While footing area increases from $36 \mathrm{~cm}^{2}(B \times L=3 \times 10 \mathrm{~cm})$ to $161 \mathrm{~cm}^{2}$ $(B \times L=7 \times 15 \mathrm{~cm})$, the ultimate loads increases about 8.3 and 6.0 times in loose and dense sand, respectively. Similarly, for the footing with dimensions of $B \times L=7 \times 15 \mathrm{~cm}$, the $q_{u}$ increases $62 \mathrm{kPa}$ to $252 \mathrm{kPa}$ while the sand gets dense. Generally, the similar figures are obtained for loose and dense sands.

\subsection{Test series II: Tests on H Shaped Footings}

In the Test Series II, the carrying loads and the bearing capacities were investigated for $\mathrm{H}$ shaped footings. A total of 10 tests have been carried out using five different footing sizes changing from $B \times L=3 \times 10 \mathrm{~cm}$ to $B \times L=6 \times 15 \mathrm{~cm}$, as listed in Table 1 Fig. 8 shows the load-settlement plots for loose and dense sand cases. As seen from the figure that the loads increase with an increase in footing size. Similar to the + shaped footings, for a constant settlement value, the loads of dense sand are greater than that of loose sand. For the case of $B \times L=5 \times 15 \mathrm{~cm}$ and $\mathrm{s}=5.0 \mathrm{~mm}$, the loads measured are $1.18 \mathrm{kN}$ and $3.24 \mathrm{kN}$ for loose and dense sands, respectively. Because of the symmetrical shape of the $\mathrm{H}$ shaped footing, the failure surfaces obtained are also symmetric.

Fig 9 presents the $Q_{u}$ and $q_{u}$ changes with A. As seen that the $Q_{u}$ and $q_{u}$ values increase with an increase in footing area in both loose and dense sands especially for smaller footing sizes. These values are derived using a method explained in Section 5.1, above. The plots start to have almost horizontal shape for the A values of around $200 \mathrm{~cm}^{2}$ and greater.

\section{Test series III: Tests on T Shaped Footings}

In this series of the test, a total of 14 tests have been carried out using seven different footing sizes changing from $B \times L=3 \times 10 \mathrm{~cm}$ to $B \times L=7 \times 15 \mathrm{~cm}$ (see, Table 1) to investigate the effects of footing size and soil density on $\mathrm{T}$ shaped foot- ings. As seen from the Fig. 10 that the loads applied increases with an increase in footing size both for loose and dense sand cases. It is also expected that, for a constant settlement value, the loads of dense sand are greater than that of loose sand. For the case of $B \times L=7 \times 15 \mathrm{~cm}$ and s $=5.0 \mathrm{~mm}$, the loads measured are $0.91 \mathrm{kN}$ and $5.88 \mathrm{kN}$ for loose and dense sands, respectively. Similar to the + and $\mathrm{H}$ shaped footings, for the loose sands at the failure stages, the loads and settlements remain almost constant and for the dense sands at the failure stages, the loads start to decrease while settlements increase. The centric load was applied on the center of gravity and therefore the heave zones concentrations occurred at the head of the $\mathrm{T}$ shaped footing both for loose and dense sands.

The plots of ultimate load and ultimate bearing capacity with footing area are shown in Fig. 11 . The $Q_{u}$ and $q_{u}$ values increase with an increase in footing area in both loose and dense sands, especially for smaller footing area. For the value of $\mathrm{A} \approx 140 \mathrm{~cm}^{2}$, there is not a distinguishing difference in $Q_{u}$ and $q_{u}$ values. Similar to the other types of footings, the soil density has an important effect. For a same footing area such that $B \times L=7 \times 15 \mathrm{~cm}$, the $Q_{u}$ and $q_{u}$ values are, $0.99 \mathrm{kN}-61.49 \mathrm{kPa}$ and $5.92 \mathrm{kN}-367.83 \mathrm{kPa}$ for the loose and dense sands, respectively.

\section{Test series IV: Tests on Square Shaped Footings}

In this Test Series IV, the carrying loads and the bearing capacities of square shaped footings rested on loose and dense soils were investigated. A total of 12 tests have been performed using six different footing widths of $B=5 ; 10 ; 15 ; 20 ; 25$ and $30 \mathrm{~cm}$. Fig. 12 shows the load-settlement curves for loose and dense sand cases. It is obviously seen that the loads increase with an increase in footing size and for a constant settlement value; the loads of dense sand are greater than that of loose sand. For the case of $B \times L=15 \times 15 \mathrm{~cm}$ and $\mathrm{s}=5.0 \mathrm{~mm}$, the loads measured are $1.57 \mathrm{kN}$ and $5.03 \mathrm{kN}$ for loose and dense 


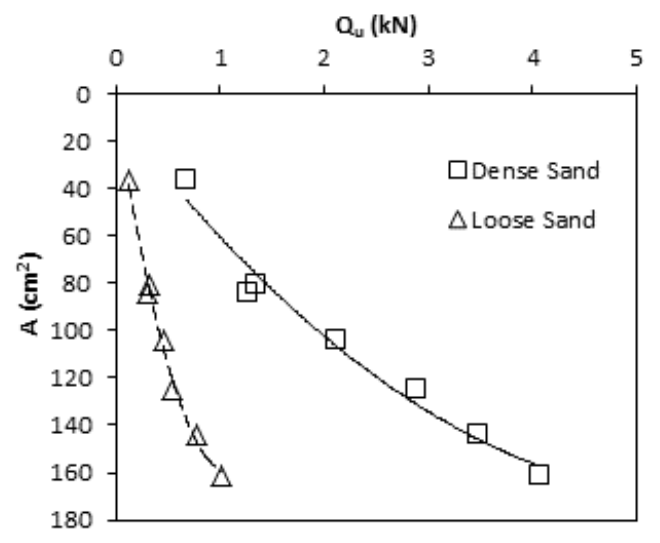

(a) Load

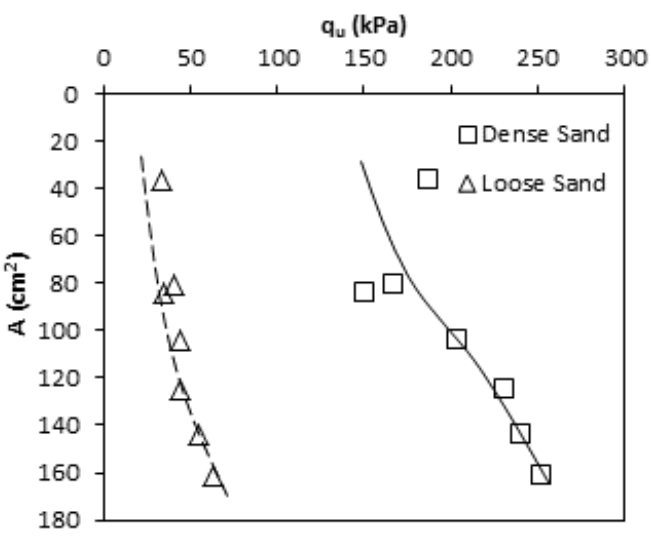

(b) Bearing capacity

Fig. 7. Ultimate values of + shaped footings for loose and dense sands

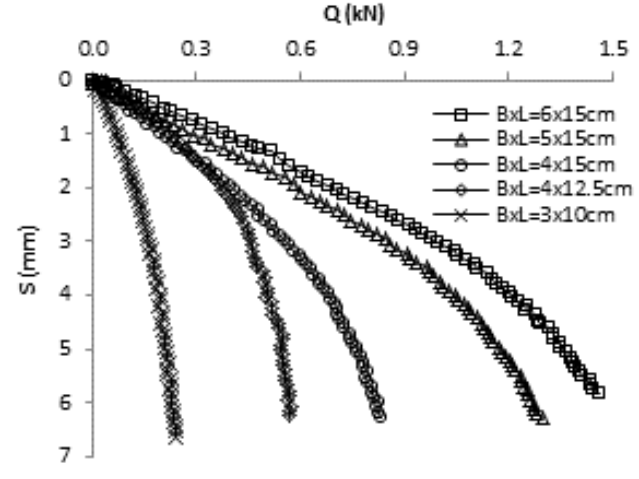

(a)

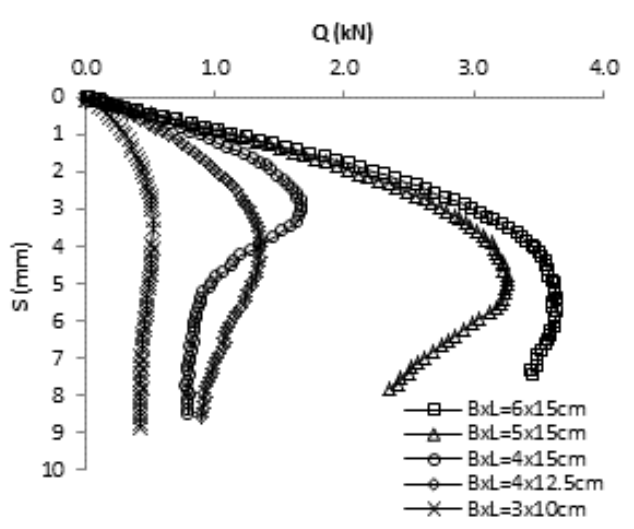

(b)

Fig. 8. Load settlement curves of $\mathrm{H}$ shaped footings for a) loose sand and b) dense sand

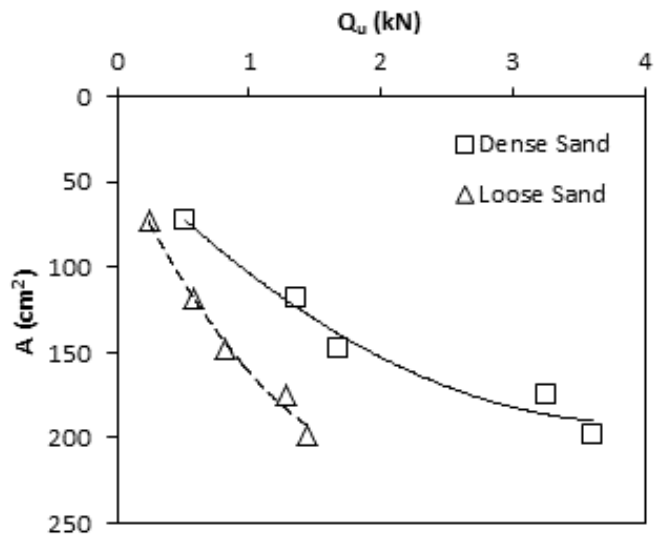

(a) Load

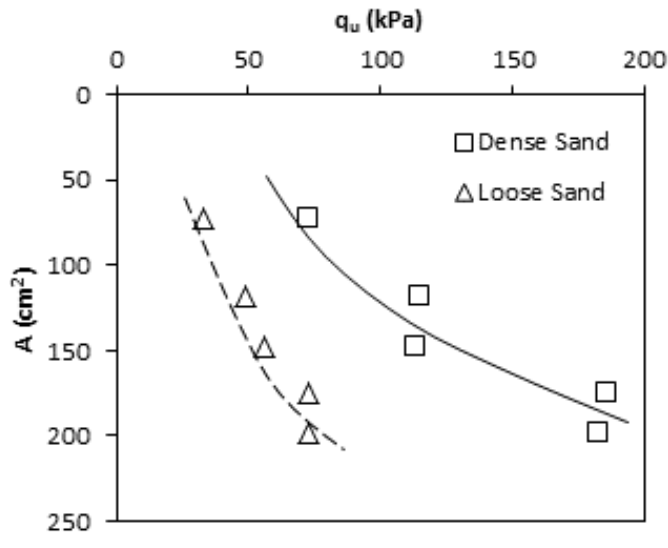

(b) Bearing capacity

Fig. 9. Ultimate values of $\mathrm{H}$ shaped footings for loose and dense sands 


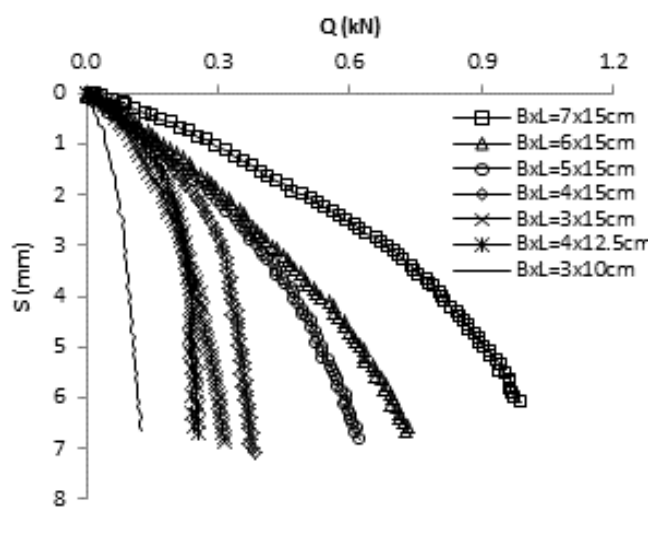

(a)

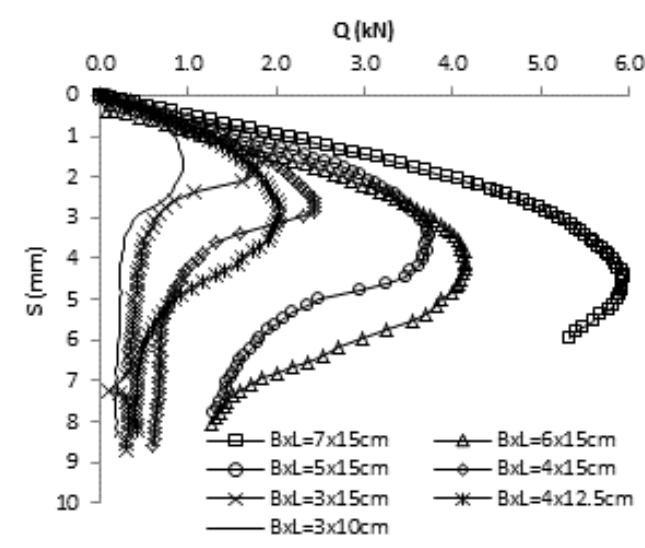

(b)

Fig. 10. Load settlement curves of $T$ shaped footings for a) loose sand and b) dense sand

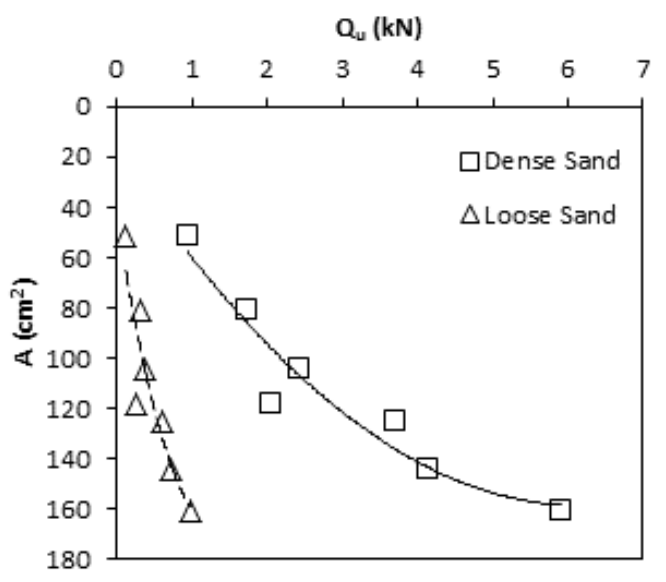

(a) Load

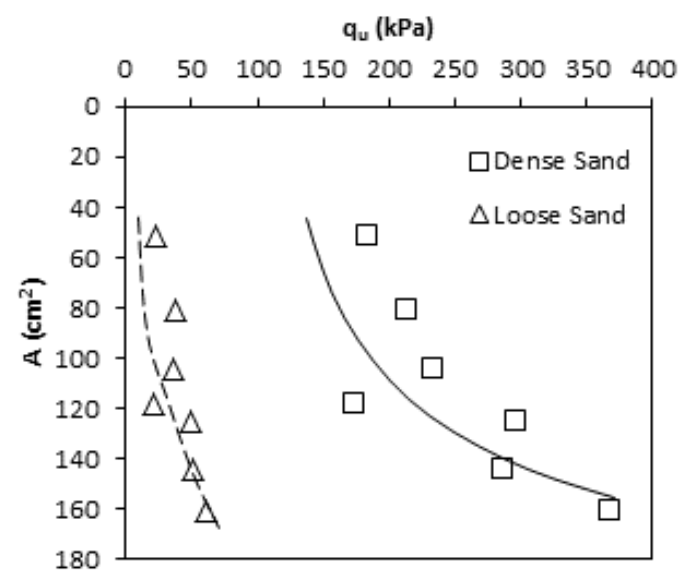

(b) Bearing capacity

Fig. 11. Ultimate values of $\mathrm{T}$ shaped footings for loose and dense sands

sands, respectively. Similar to the + and $\mathrm{H}$ shaped footings, the symmetrical failure surfaces and therefore the symmetrical heave zones were obtained.

Fig. 13 shows the changes of $Q_{u}$ and $q_{u}$ according to a. As seen from the Fig. 13 (a) that the $Q_{u}$ values increase with an increase in footing area in both loose and dense sands. For example, the calculated $Q_{u}$ values for $B \times L=10 \mathrm{~cm}$ and $B \times L=30 \mathrm{~cm}$ are $[0.60 \mathrm{kN}-$ loose; $1.32 \mathrm{kN}$-dense $]$ and $[5.22 \mathrm{kN}$ loose; $13.28 \mathrm{kN}$-dense], respectively. It is also seen that the soil density has an important effect on the load carried. When the ultimate bearing capacities of the square footings are considered, it is concluded that there is not a distinguishing difference between bearing capacity of square footings, especially for the larger footing sizes. Bearing capacities for the loose sand case are obtained approximately $73.38 \mathrm{kPa} ; 65.80 \mathrm{kPa} ; 56.78 \mathrm{kPa}$ and $57.99 \mathrm{kPa}$ for $15 \mathrm{~cm} ; 20 \mathrm{~cm} ; 25 \mathrm{~cm}$ and $30 \mathrm{~cm}$ widths, respectively.

Table 4 shows the shape effect of the footings on the ultimate load and the ultimate bearing capacity. The footings in this table are selected because they have nearly the same loading area. The $Q_{u}$ and $q_{u}$ values are obtained using the method explained in Section 5.1. It is concluded from the Table 4 that there is not a great difference between bearing capacity of multi-edge footings (,$+ \mathrm{H}$ and $\mathrm{T}$ shaped) and square footing when they are of the nearly same area. Generally, the $Q_{u}$ and $q_{u}$ values fall into the similar band both in loose and dense sands. The differences in these values can be resulted from the methodology of the testing. Ghazavi and Mokhtari [14] reported similar findings. They concluded that there is not a distinguishing difference between bearing capacity of multi-edge foundations and square foundation when they are of the same area.

\section{Overview of artificial neural networks}

Artificial neural networks are a form of artificial intelligence, which by means of their architecture, try to simulate the behavior of the human brain and nervous system. They have the ability to relate between the input data and corresponding output data which can be defined depending on single or multiple parameters for solving a linear or nonlinear problem. Artificial neural networks do not require any prior knowledge and a physical model about the problem to solve it. The nature of the relationship between the input and output parameters are captured by 


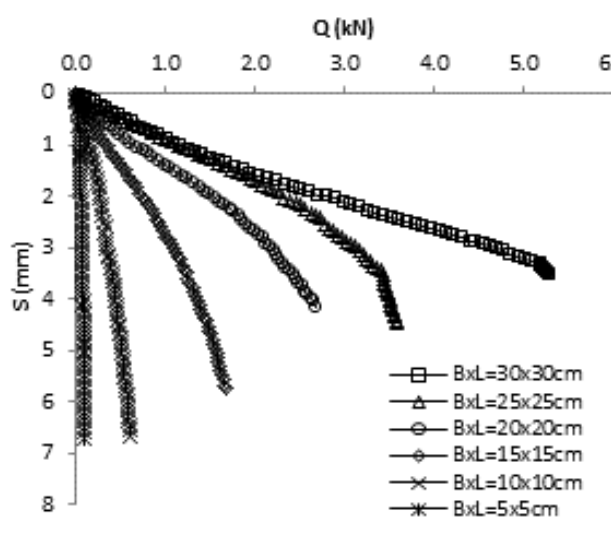

(a)

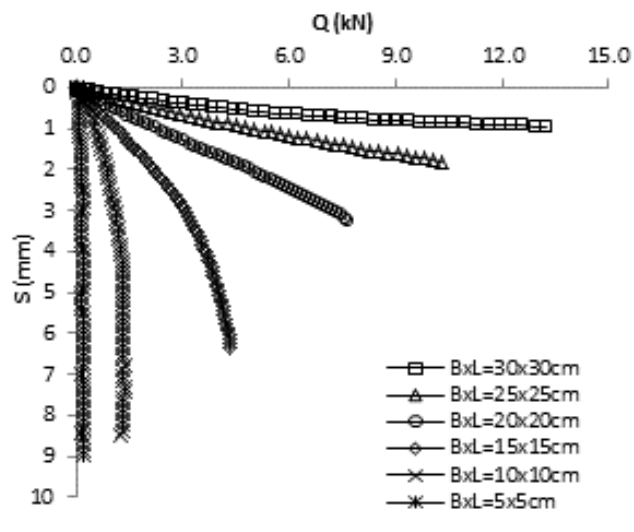

(b)

Fig. 12. Load settlement curves of square shaped footings for a) loose sand and b) dense sand

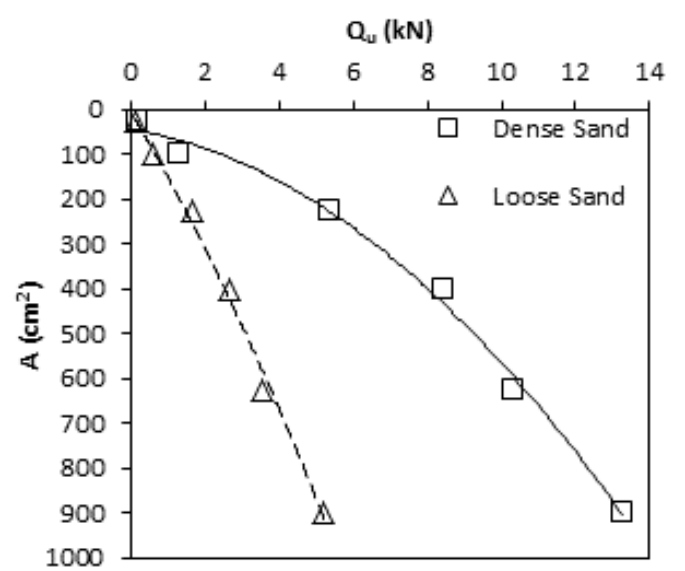

(a) Load

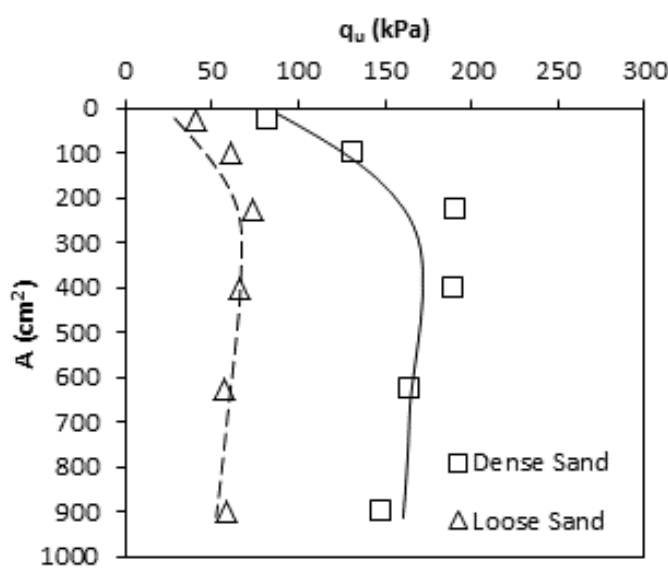

(b) Bearing capacity

Fig. 13. Ultimate values of square shaped footings for loose and dense sands

Tab. 4. Shape effect on ultimate load and ultimate bearing capacity

\begin{tabular}{|c|c|c|c|c|c|c|}
\hline $\begin{array}{l}\text { Footing } \\
\text { Type }\end{array}$ & $\begin{array}{c}\text { Footing } \\
\text { Width B } \\
\text { (cm) }\end{array}$ & $\begin{array}{l}\text { Footing } \\
\text { Length L } \\
\quad(\mathrm{cm})\end{array}$ & $\begin{array}{c}\text { Footing } \\
\text { Area A } \\
\left(\mathrm{cm}^{2}\right)\end{array}$ & $\begin{array}{l}\text { Ultimate } \\
\text { Load } Q_{u} \\
\quad(\mathbf{k N})\end{array}$ & $\begin{array}{c}\text { Ultimate } \\
\text { Bearing } \\
\text { Capacity } q_{u} \\
(\mathrm{kPa})\end{array}$ & Soil Density \\
\hline+ & 4 & 15.0 & 104 & 455 & 43.75 & \multirow{4}{*}{ Loose } \\
\hline $\mathrm{H}$ & 4 & 12.5 & 118 & 576 & 48.81 & \\
\hline$T$ & 4 & 15.0 & 104 & 370 & 35.58 & \\
\hline Square & 10 & 10.0 & 100 & 303 & 30.30 & \\
\hline+ & 4 & 15.0 & 104 & 2119 & 203.75 & \multirow{4}{*}{ Dense } \\
\hline $\mathrm{H}$ & 4 & 12.5 & 118 & 1351 & 144.49 & \\
\hline$T$ & 4 & 15.0 & 104 & 2424 & 233.08 & \\
\hline Square & 10 & 10.0 & 100 & 1348 & 134.80 & \\
\hline
\end{tabular}


means of learning of samples in the data set [20, 34]. Artificial neural networks can be applied successfully for the solution of the problems which have no specific solutions and too complex to be modelled by the mathematical and traditional methods [1.38]. A comprehensive description of ANNs can be found in many publications [18, 28, 34, 41].

In this study the artificial neural network approach, namely multi-layer perceptron (MLP), and multi-linear regression model (MLR) were used. Results of the field studies were compared with those obtained by the MLP and MLR approaches.

An MLP distinguishes itself by the presence of one or more hidden layers, whose computation nodes are correspondingly called hidden neurons of hidden units. A MLP network structure is shown in Fig. 14 The function of hidden neurons is to intervene between the external input and the network output in some useful manner. The numbers of hidden layer neurons are found using simple trial-and-error method in all applications. The sigmoid and linear functions are used for the activation functions of the hidden and output nodes, respectively. The detailed theoretical information about MLP can be found in Haykin [17]. Here, the MLP is trained using Levenberg-Marquardt technique due to fact that this technique is more powerful and faster than the conventional gradient descent technique [11,16].

A typical structure of artificial neural networks consists of a number of processing elements, or nodes, that are usually arranged in layers: an input layer, an output layer and one or more hidden layers (Fig. 14) [17].

Each processing element in a specific layer is fully or partially joined to many other processing elements via weighted connections. The input from each element in the previous layer $\left(x_{i}\right)$ is multiplied by an adjustable connection weight $\left(w_{j i}\right)$. At each element, the weighted input signals are summed and a threshold value or bias $\left(\theta_{j}\right)$ is added. This combined input $\left(I_{j}\right)$ is then passed through a nonlinear transfer function $(f()$.$) (e.g.$ sigmoidal transfer function and tanh transfer function) to produce the output of the processing elements $\left(y_{j}\right)$. The output of one processing element provides the input to the processing elements in the next layer. This process is summarized in Eq. (1) and Eq. (2) and illustrated in Fig. 14.

$$
\begin{gathered}
I_{j}=\sum w_{j i} x_{i}+\theta_{j} \quad \text { summation } \\
y_{j}=f\left(I_{j}\right) \quad \text { transfer }
\end{gathered}
$$

The propagation of information in artificial neural networks starts at the input layer where the network is presented with a historical set of input data and the corresponding (desired) outputs. The actual output of the network is compared with the desired output and an error is calculated. Using this error and utilising a learning rule, the network adjusts its weights until it can find a set of weights that will produce the input/output mapping that has the smallest possible error. This process is called "learning" or "training". It should be noted that a network with one hidden layer can approximate any continuous function provided that sufficient connection weights are used [8, 19]. The objective of the learning is to capture the relationship between the input and output parameters. For this purpose network models are trained using by learning algorithm. The LevenbergMarquardt algorithm is an approximation to Newton's method, and Hagan and Menhaj [16] showed that it is very efficient for training networks which have up to a few hundred weights. Although the computational load of the Levenberg-Marquardt algorithm is greater than the other techniques, this is compensated by the increased efficiency and much better precision in results. In many cases the Marquardt algorithm was found to converge when other back-propagation techniques diverged [16]. If there is a function, $V(x)$, which is to be minimized with respect to the parameter vector, $x$, then Newton's method would be

$$
\Delta x=-\left[\nabla^{2} V(x)\right]^{-1} \nabla V(x)
$$

where $\nabla^{2} V(x)$ is the Hessian matrix and $\nabla V(x)$ is the gradient. If we assume that $V(x)$ is a sum of squares function

$$
V(x)=\sum_{i=1}^{N} e_{i}^{2}(x)
$$

then it can be shown that

$$
\begin{gathered}
\nabla V(x)=J^{T}(x) e(x) \\
\nabla^{2} V(x)=J^{T}(x) J(x)+S(x)
\end{gathered}
$$

where $J(x)$ is the Jacobean matrix and $S(x)$ described as follows

$$
S(x)=\sum_{i=1}^{N} e_{i}(x) \nabla^{2} e_{i}(x)
$$

For the Gauss-Newton method it is assumed that $S(x) \approx 0$, and the update of Eq. (3) becomes

$$
\Delta x=\left[J^{T}(x) J(x)\right]^{-1} J^{T}(x) e(x)
$$

The Levenberg-Marquardt modification to the Gauss-Newton method is

$$
\Delta x=\left[J^{T}(x) J(x)+\mu I\right]^{-1} J^{T}(x) e(x)
$$

The parameter $\mu$ is multiplied by a $\beta$ factor whenever a step would result in an increased $V(x)$. When a step reduces $V(x)$, $\mu$ is divided by $\beta$. When $\mu$ is large the algorithm becomes steepest descent (with step $1 / \mu$ ), while for small $\mu$ the algorithm becomes Gauss-Newton. The Levenberg-Marquardt algorithm can be considered a trust-region modification to Gauss-Newton. The key step in this algorithm is the computation of the Jacobean matrix. For the neural network-mapping problem, the terms in the Jacobean matrix can be computed by a simple modification to the back-propagation algorithm [29]. 


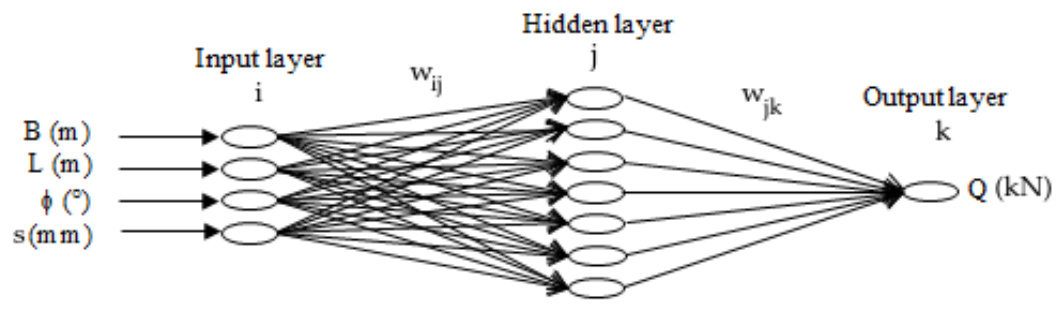

Fig. 14. The chosen model architecture

The great majority of the civil engineering application of neural networks is based on use of the Back-propagation (BP) algorithm primarily because of its simplicity [27]. In the BP algorithm, training is supervised such that the network connection weights are adjusted according to the sum of the squares of differences between actual and target outputs.

The goal of the training is to reduce the error function iteratively, defined in the form of the sum of the squares of the errors between actual outputs and target outputs. Global error, $E$, can be defined as;

$$
E=\frac{1}{p} \sum_{p=1}^{p} E_{p}
$$

where $p$ is the total number of training samples and $E_{p}$ is the error for training sample $p$.

$E_{p}$ is calculated by following equation;

$$
E_{p}=\frac{1}{2} \sum_{i=1}^{N}\left(o_{i}-t_{i}\right)^{2}
$$

In this equation, $N, o_{i}$ and $t_{i}$ represent the total number of the output neurons, the network output at the $i^{\text {th }}$ output neuron and the target output at the $i^{\text {th }}$ output neuron, respectively [28, 34]. The information related to the theory and applications of ANNs may be found in Rumelhart and McClelland [32].

\section{Artificial neural network applications}

In this study, artificial neural networks were used for prediction of ultimate loads of multi- edge footings supported by loose and dense sand beds. For this purpose multilayer feed forward network models have been trained using by LM learning algorithm. The data used in running of network models have been obtained from the laboratory model tests explained above. Details of the laboratory model tests are given in Section 2 to 6 .

The problem is proposed to network models by means of four input parameters representing the width of the footing $(B)$, the length of the footing $(L)$, internal friction angle of soil $(\varphi)$, settlement of the footing $(s)$ and one output parameter representing $\operatorname{load}(Q)$.

It is common practice to split the available data into two subsets: a training set and an independent validation set [28]. The literature offers little guidance in selecting the size of training and the test sample. Most authors select the ratio of training data versus testing data depending on their particular problems
[10, 22, 36]. So, a total of 2682 individual data samples obtained from experimental studies were used for training and testing of network models. The available data set were divided into two groups as training and testing data sets which consist of 1999 and 683 data samples, respectively. Data samples were selected randomly from the available data set to constitute mentioned data sets. One important aspect here is to make sure that the minimum and maximum of the testing data set falls within the minimum and maximum of the training dataset. The statistical properties and range of the parameters are shown in Table 5 and Table 6, respectively. In Table 5, the parameters, $X_{\min }$, $X_{\text {max }}, X_{\text {mean }}, S_{x}$ and $C_{s x}$ refer to the minimum value, the maximum value, the mean value, the standard deviation value and the skewness coefficient of the training and testing data sets, respectively.

Tab. 5. The statistical properties of data sets

\begin{tabular}{cccccc}
\hline \multicolumn{7}{c}{ TRAINING DATA SET } \\
\hline \multicolumn{7}{c}{$X_{\min }$} & $X_{\max }$ & $X_{\text {mean }}$ & $S_{x}$ & $C_{s x}$ \\
\hline$B(\mathrm{~m})$ & 0.00 & 0.30 & 0.08 & 0.07 & 2.08 \\
\hline$L(\mathrm{~m})$ & 0.10 & 0.30 & 0.15 & 0.05 & 1.35 \\
\hline$\varphi\left(^{\circ}\right)$ & 36.00 & 42.00 & 38.54 & 2.97 & 0.31 \\
\hline$S(\mathrm{~mm})$ & 0.00 & 7.07 & 2.46 & 1.79 & 0.54 \\
\hline$Q(\mathrm{kN})$ & 0.00 & 13.28 & 1.27 & 1.71 & 2.65 \\
\hline \multicolumn{7}{c}{ TEST DATA SET } \\
\hline$B(\mathrm{~m})$ & 0.00 & 0.25 & 0.09 & 0.07 & 1.07 \\
\hline$L(\mathrm{~m})$ & 0.10 & 0.25 & 0.15 & 0.03 & 1.13 \\
\hline$\varphi\left({ }^{\circ}\right)$ & 36.00 & 42.00 & 37.98 & 2.82 & 0.73 \\
\hline$S(\mathrm{~mm})$ & 0.00 & 6.67 & 2.60 & 1.83 & 0.41 \\
\hline$Q(\mathrm{kN})$ & 0.00 & 10.31 & 1.35 & 1.72 & 2.35 \\
\hline
\end{tabular}

Tab. 6. The ranges of the parameters

\begin{tabular}{cccc}
\hline Model variables & Minimum value & Maximum value & Range \\
\hline$B(\mathrm{~m})$ & 0.00 & 0.30 & 0.30 \\
\hline$L(\mathrm{~m})$ & 0.10 & 0.30 & 0.20 \\
\hline$\varphi\left(^{\circ}\right)$ & 36.00 & 42.00 & 6.00 \\
\hline$S(\mathrm{~mm})$ & 0.00 & 7.07 & 7.07 \\
\hline$Q(\mathrm{kN})$ & 0.00 & 13.28 & 13.28 \\
\hline
\end{tabular}

To develop the best network model, given the available data set, the training data set should contain all representative samples that are present in the available data set [35]. As seen in Table 5, data sets represent the same problem domain such that 
Tab. 7. The saved weights from input layer to hidden layer

\begin{tabular}{ccccc}
\hline Hidden Layer & \multicolumn{4}{c}{ Input Variables $\left(I_{I}\right)$} \\
\cline { 2 - 5 } Neuron Number $H_{j}$ & $\mathbf{I}_{\mathbf{1}}$ & $\mathbf{I}_{\mathbf{2}}$ & $\mathbf{I}_{\mathbf{3}}$ & $\mathbf{I}_{\mathbf{4}}$ \\
\hline$H_{1}$ & -0.7896 & -6.2162 & 5.5165 & -5.0917 \\
\hline$H_{2}$ & -1.0301 & -0.7131 & -5.1160 & -3.3963 \\
\hline$H_{3}$ & 0.4126 & -8.5326 & 2.3984 & -0.6776 \\
\hline$H_{4}$ & -1.3430 & -3.5226 & -5.5350 & -4.9952 \\
\hline$H_{5}$ & 5.2560 & -4.3348 & -5.689 & -128.9850 \\
\hline$H_{6}$ & 4.3888 & -6.9690 & 0.1306 & -2.6695 \\
\hline$H_{7}$ & -5.0521 & 6.7447 &
\end{tabular}

Tab. 8. The saved weights from hidden layer to output layer

\begin{tabular}{cccccccc}
\hline Output Neuron & \multicolumn{7}{c}{ Hidden Layer Neuron Number $\left(H_{J}\right)$} \\
\hline Number $\left(O_{w}\right)$ & $\mathbf{H}_{\mathbf{1}}$ & $\mathbf{H}_{\mathbf{2}}$ & $\mathbf{H}_{\mathbf{3}}$ & $\mathbf{H}_{\mathbf{4}}$ & $\mathbf{H}_{\mathbf{5}}$ & $\mathbf{H}_{\mathbf{6}}$ & $\mathbf{H}_{\mathbf{7}}$ \\
\hline$O_{1}$ & -0.1454 & -5.1504 & 4.9205 & -0.0652 & -0.1291 & 0.1372 & -0.0114 \\
\hline
\end{tabular}

the statistical properties of the data sets are consistent with each other. In any model development process, familiarity with the available data is of the utmost importance. Generally, different variables span different ranges. In order to ensure that all variables receive equal attention during the training process, they should be standardized.

Preprocessing of the data is usually required before presenting the data samples to the network model when the neurons have a transfer function with bounded range. The reasons for scaling of the data samples can be described as to initially equalize the importance of variables and to improve interpretability of network weights [15].

Determining an appropriate architecture of a neural network for a particular problem is an important issue, since the network topology directly affects its computational complexity and its generalization capability [22]. Multilayer feed forward network models with one hidden layer can approximate any complex nonlinear function provided sufficiently many hidden layer neurons are available. Therefore, in this study, multilayer feed forward network models containing one hidden layer were used.

Determination of optimum number of the hidden layer neurons is very important in order to predict accurately a parameter using by artificial neural networks. But there is no theory how many hidden layer neuron need to be used for a particular problem. For that reason, generally, numbers of hidden layer neurons have been determined by trial-error method. A common strategy for finding the optimum number of hidden layer neurons is to start with a few numbers of neurons and increasing the number of neurons while monitoring the performance criteria, until no significant improvement is observed [15, 30].

In this study, the performance of various network models with different hidden layer neuron number was examined to choose an appropriate number of hidden layer neurons. Hence, 2 neurons were used in the hidden layer at the beginning of the process then the neuron number was increased step-by-step adding 1 neuron until no significant improvement is noted.
MLR technique was applied to both testing and training dataset. The following formulas, using MLR technique, were found to offer the best statistical measures for fit of testing and training datasets, respectively:

$$
Q=-13.40+0.35 s+9.12 B+12.10 L+0.292 \varphi
$$

where, $Q(\mathrm{kN})$ is load, $s(\mathrm{~mm})$ is the footing settlement, $B(\mathrm{~m})$ is the width of the footing, $L(\mathrm{~m})$ is the footing length and $\varphi\left({ }^{\circ}\right)$ is the internal friction angle.

The network models tried were compared according to the mean absolute relative error (MARE), the mean square error (MSE) and coefficient of determination $\left(R^{2}\right)$ criteria. These criteria are defined as;

$$
\begin{gathered}
\text { MARE }=\frac{1}{N} \sum_{i=1}^{N} \frac{\left|M_{i_{\text {meassured }}}-M_{i_{\text {predicted }}}\right|}{M_{i_{\text {measured }}}} \cdot 100 \\
M S E=\frac{\sum_{i=1}^{N}\left(M_{i_{\text {measured }}}-M_{i_{\text {predicted }}}\right)^{2}}{N}
\end{gathered}
$$

$$
\begin{aligned}
& R^{2}= \\
& =\frac{\sum_{i=1}^{p}\left[M_{i_{\text {measured }}}-\bar{M}_{i_{\text {measured }}}\right]^{2}-\sum_{i=1}^{p}\left[M_{i_{\text {measured }}}-M_{i_{\text {prediced }}}\right]^{2}}{\sum_{i=1}^{p}\left[M_{i_{\text {measured }}}-\bar{M}_{i_{\text {measured }}}\right]^{2}}
\end{aligned}
$$

In these equations $N$ and $M$ denote the total number of the data samples and bearing capacity, respectively.

End of these processes the best performance was obtained from ANN model which has 7 neurons in the hidden layer. The chosen model architecture is shown in Fig. 14.

Training of the network models is carried out by presenting training data set involving input-output data pairs. The connection weights are adjusted during the training phase according to the differences between the target output $\left(M_{\text {measured }}\right)$ and the actual output $\left(M_{\text {predicted }}\right)$ [23]. 
The adjustment of the connection weights are continued until the mean square error over all the training samples falls below a given value or the maximum number of epoch is reached. In the training phase, the performance of the network models is monitored at each epoch using test data set. Overfitting of the network model is prevented with this way. When training phase was over the weights are saved for using in the test phase. The saved weights and biases values used by chosen network model with 7 hidden layer neurons are presented in Table 7 Table 8 and Table 9 respectively.

Tab. 9. The saved biases values

\begin{tabular}{cc}
\hline Neuron number & Bias values \\
\hline$H_{1}$ & 3.6254 \\
\hline$H_{2}$ & 7.8073 \\
\hline$H_{3}$ & 9.2571 \\
\hline$H_{4}$ & 5.1371 \\
\hline$H_{5}$ & -4.5568 \\
\hline$H_{6}$ & 4.9537 \\
\hline$H_{7}$ & 2.6529 \\
\hline$O_{1}$ & 0.3680 \\
\hline
\end{tabular}

To compare the results obtained from network and regression models with the experimental results, predicted values were transformed back to their original values and then MARE and MSE were computed.

The tangent sigmoid, logarithmic sigmoid and pure linear transfer functions were tried as activation functions for hidden and output layer neurons to determine the best network model [17]. The most appropriate results have been obtained from chosen network model in which tangent sigmoid and pure linear functions used as activation function for the hidden and output layer neurons, respectively. The program used in running the network models was written in Matlab language code.

The MSE (mean square error), MARE (mean absolute relative error), and $R^{2}$ (determination coefficient) values of MLP and MLR, for both training and testing phases are given in Table 10

Tab. 10. The results obtained from the chosen network model and regression model

\begin{tabular}{ccc}
\hline & MLP & MLR \\
\hline Train MSE $(\mathrm{kPa})$ & 0.09 & 1.19 \\
\hline Test MSE $(\mathrm{kPa})$ & 0.23 & 0.95 \\
\hline Train MARE & 94.40 & 1165.73 \\
\hline Test MARE & 111.65 & 627.60 \\
\hline$R_{\text {train }}^{2}$ & 0.968 & 0.593 \\
\hline$R_{\text {test }}^{2}$ & 0.949 & 0.680 \\
\hline Epoch number & 24 & - \\
\hline Hidden layer neurons & 7 & - \\
\hline
\end{tabular}

As seen from Table 10 that the MLP model has the smaller MSE (0.09), and MARE (94.40) and the highest $R^{2}$ (0.968) for training phase. It also has the smaller MSE (0.23) and MARE (111.65) and higher $R^{2}(0.949)$ for testing phase. According to this statistical analysis, the MLP estimations are better than those of the MLR and also produce more accurate results than the MLR. It can be seen from Table 10 that the ANN method performs better than the MLR both in training and testing phases. In other words, the neural network is able to successfully model the bearing capacity of shallow footings resting on clay soil.

Fig. 15 and Fig. 16 present the measured bearing capacities versus predicted bearing capacities by network model with $R^{2}$ coefficients for training and testing phases, respectively. The linear 1:1 lines were also plotted in these figures to discuss the performance of statistical models. It is seen from the figures that for artificial neural network (ANN) model approach, the location points of measured and predicted bearing capacity values are scattered around 1:1 lines for both training and testing phases. On the other hand the multi-linear regression model gives results in a broad band, especially in training phase. The prediction performance increases from $59.3 \%$ to $96.8 \%$ for training phase and from $68.0 \%$ to $94.9 \%$ for testing phase, when the determination coefficients $\left(R^{2}\right)$ were considered. It is concluded that a statistical model based on artificial neural network approach, namely MLP, is also proposed as an alternative to MLR technique. MLP produced more accurate results than that of the MLR technique.

\section{Limitations}

There are several limitations that should be mentioned. It is well known that, full-scale loading test results are valid especially for in-situ conditions and for soil properties in which the test was performed. However, a full-scale loading test is not economic due to the expensive cost in time and money required for construction, instrumentation and testing. Therefore, small-scale model test studies are used widely as an alternative to full-scale loading tests, despite of their scale-errors [9]. Then, the tests were conducted on only one soil type. The results observed from this test program may be different for other soils. Additionally, only surface footings were tested. The effect of footing embedment should also be included in future works. These additional researches are recommended as further investigations to improve the understanding of the bearing capacity behavior comprehensively, which may lead to developing a design method.

\section{Conclusions}

In this study, laboratory model tests were performed using four types of multi-edge footings under two different soil densities. A total of four different test Series were performed including the 25 different footing sizes. At the end of the tests, load settlement curves were plotted and artificial neural networks (ANNs) and multi-linear regression model (MLR) used for prediction of carrying load and bearing capacity of multiedge footings over loose and dense sand soil. Based on the results from this investigation, the following main conclusions can be drawn:

- For the multi-edge footings, the loads increase with an increase in footing size both for loose and dense sand cases. 


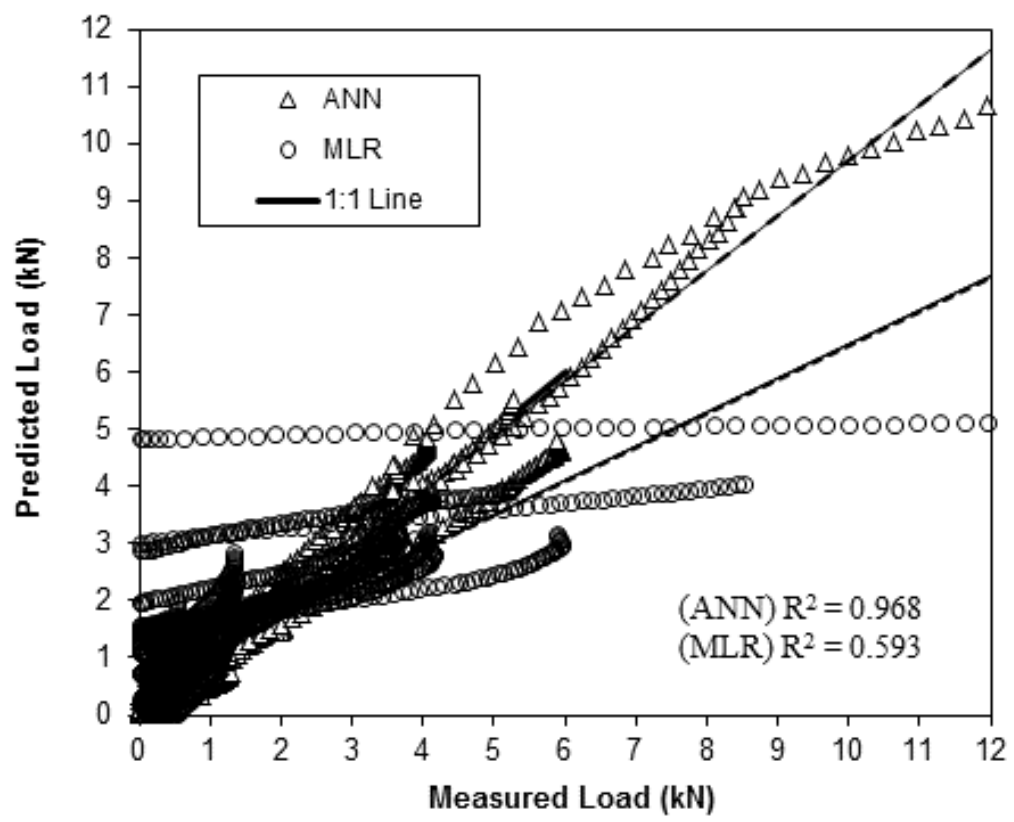

Fig. 15. The correlation between the measured and predicted bearing capacities in the training phase

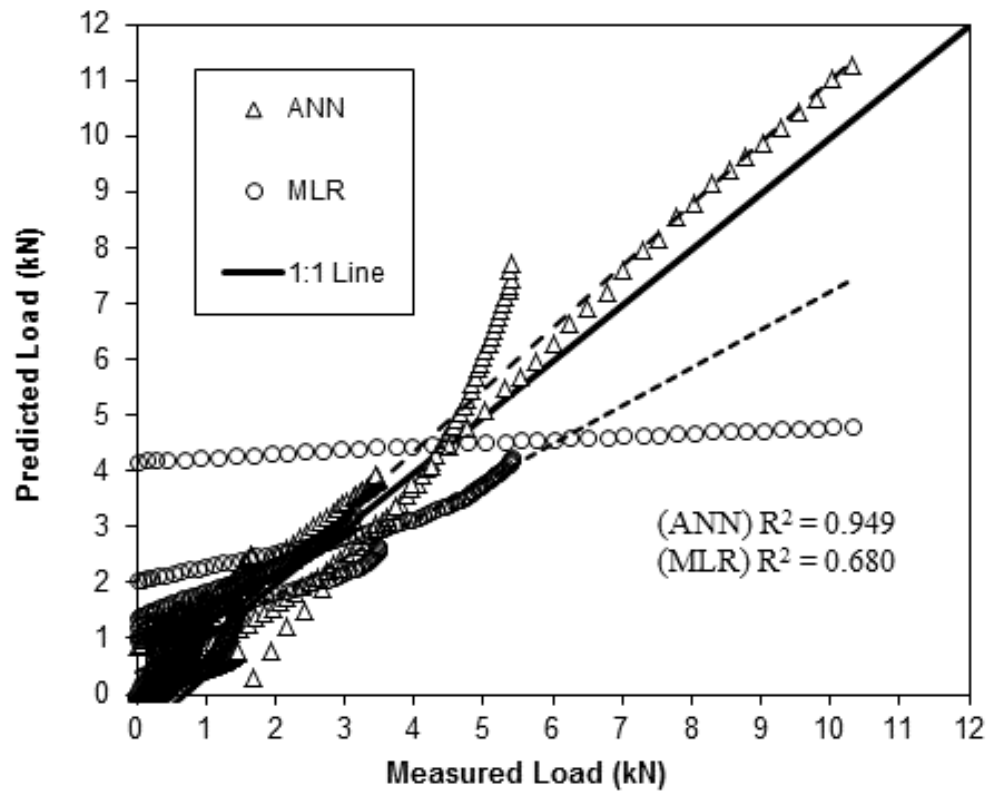

Fig. 16. The correlation between the measured and predicted bearing capacities in the testing phase 
Similarly, for a constant settlement value, the loads of dense sand are greater than that of loose sand.

- The ultimate load and ultimate bearing capacity increase with an increase in footing area in both loose and dense sands.

- For + shaped footings; while footing area increases from $36 \mathrm{~cm}^{2}(B \times L=3 \times 10 \mathrm{~cm})$ to $161 \mathrm{~cm}^{2}(B \times L=7 \times 15 \mathrm{~cm})$, the ultimate loads increases about 8.3 and 6.0 times in loose and dense sand, respectively. For $\mathrm{H}$ shaped footings; for the case of $B \times L=5 \times 15 \mathrm{~cm}$ and $\mathrm{s}=5.0 \mathrm{~mm}$, the loads measured are $1.18 \mathrm{kN}$ and $3.24 \mathrm{kN}$ for loose and dense sands, respectively. For T shaped footings, for the case of $B \times L=7 \times 15 \mathrm{~cm}$ and $s=5.0 \mathrm{~mm}$, the loads measured are $0.91 \mathrm{kN}$ and $5.88 \mathrm{kN}$ for loose and dense sands, respectively. Bearing capacities for the loose sand case are obtained approximately $73.38 \mathrm{kPa}$; $65.80 \mathrm{kPa} ; 56.78 \mathrm{kPa}$ and $57.99 \mathrm{kPa}$ for $15 \mathrm{~cm} ; 20 \mathrm{~cm} ; 25 \mathrm{~cm}$ and $30 \mathrm{~cm}$ widths, respectively.

- For the,$+ \mathrm{H}$ and $\mathrm{T}$ shaped footings, for the loose sands at the failure stages, the loads and settlements remain almost constant, and for the dense sands at the failure stages, the loads start to decrease while settlements increase.

- There is not a great difference between bearing capacity of multi-edge footings (+, $\mathrm{H}$ and $\mathrm{T}$ shaped) and square footing when they are of the nearly same area. Generally, the ultimate load and ultimate bearing capacity values fall into the similar band both in loose and dense sands.

- The artificial neural network model serves as simple and reliable tool for the ultimate load of multi-edge footings over loose and dense sands. The results produced high coefficients of correlation for the training and testing data of 0.968 and 0.949 , respectively.

- A statistical model based on artificial neural network approach, namely MLP, is also proposed as an alternative to MLR technique. MLP produced more accurate results than that of the MLR technique, MLP gave better results between them in terms of MSE $(=0.09)$, MARE $(=94.40 \%)$ and $R^{2}$ $(=0.968)$ statistics.

Nevertheless the investigation is considered to have provided a useful basis for further research leading to an increased understanding of the application of multi-edge footings to bearing capacity problems.

\section{References}

1 Adeli H, Neural Networks in Civil Engineering: 1989-2000, ComputerAided Civil and Infrastructure Engineering, 16(2), (2001), 126-142, DOI 10.1111/0885-9507.00219

2 Basma AA, Kallas N, Modeling soil collapse by artificial neural networks, Geotechnical and Geological Engineering, 22(3), (2004), 427-438, DOI 10.1023/B:GEGE.0000025044.72718.db

3 Bransby MF, Randolph MF, The Effect of Embedment Depth on the Undrained Response of Skirted Foundations to Combined Loading., Soils and Foundations, 39(4), (1999), 19-34, DOI 10.3208/sandf.39.4_19
4 Bransby MF, Randolph MF, The effect of skirted foundation shape on response to combined $V$-M-H loadings, International Journal of Offshore and Polar Engineering, 9(3), (1999), 214-218.

5 Brinkgreve RBJ, Swolfs WM, Engin E, Plaxis finite element code for soil and rock analysis, Balkema Press, 2011.

6 Cho SE, Probabilistic stability analyses of slopes using the ANN-based response surface, Computers and Geotechnics, 36(5), (2009), 787-797, DOI 10.1016/j.compgeo.2009.01.003

7 Cobaner M, Haktanir T, Kisi O, Prediction of Hydropower Energy Using ANN for the Feasibility of Hydropower Plant Installation to an Existing Irrigation Dam, Water Resources Management, 22(6), (2008), 757-774, DOI 10.1007/s11269-007-9190-z

8 Cybenko G, Approximation by superpositions of a sigmoidal function, Mathematics of Control, Signals, and Systems, 2(4), (1989), 303-314, DOI 10.1007/BF02551274

9 Dickin EA, Nazir R, Moment-Carrying Capacity of Short Pile Foundations in Cohesionless Soil, Journal of Geotechnical and Geoenvironmental Engineering, 125(1), (1999), 1-10, DOI 10.1061/(ASCE)10900241(1999)125:1(1)

10 Dogan A, Demirpence H, Cobaner M, Prediction of groundwater levels from lake levels and climate data using ANN approach, Water SA, 34(2), (2008), 199-208.

11 El-Bakyr MY, Feed forward neural networks modeling for K-P interactions, Chaos, Solutions and Fractals, 18(5), (2003), 995-1000, DOI 10.1016/S0960-0779(03)00068-7

12 Fausett LV, Fundamentals Neural Networks: Architecture, Algorithms and Applications, Prentice-Hall, Englewood Cliffs; New Jersey, 1994.

13 Ghazavi M, Bearing capacity of multi-edge foundations, M.S. thesis, K.N.T. University of Technology; Tehran, Iran, 2005.

14 Ghazavi M, Mokhtari S, Numerical investigation of load-settlement characteristics of multi-edge shallow foundations, The 12th International Conference of International Association for Computer Methods and Advances in Geomechanics, In:; Goa, India, 2008.

15 Goh ATC, Back-propagation neural networks for modeling complex systems, Artificial Intelligence in Engineering, 9(3), (1995), 143-151, DOI 10.1016/0954-1810(94)00011-S

16 Hagan MT, Menhaj MB, Training feed forward networks with the Marquardt algorithm, IEEE Trans Neural Networks, 5(6), (1994), 861-867.

17 Haykin S, Neural Networks - A Comprehensive Foundation, Prentice-Hall, Upper Saddle River, 1998.

18 Hecht-Nielsen R, Neurocomputing, Addison-Wesely Publishing Company Reading, 1990.

19 Hornik K, Stinchcombe M, White H, Multilayer feedforward networks are universal approximators, Neural Networks, 2(5), (1989), 359-366, DOI 10.1016/0893-6080(89)90020-8

20 Juang $\mathbf{C H}$, Jiang T, Christopher RA, Three-dimensional site characterisation: neural network approach, Geotechnique, 51(9), (2001), 799-809, DOI $10.1680 /$ geot.2001.51.9.799

21 Kayadelen C, Estimation of effective stress parameter of unsaturated soils by using artificial neural networks, International Journal for Numerical and Analytical Methods in Geomechanics, 32(9), (2008), 1087-1106, DOI 10.1002/nag.660

22 Kisi O, Suspended sediment estimation using neuro-fuzzy and neural network approaches, Hydrological Sciences Journal, 50(4), (2005), 683-696.

23 Kisi O, Uncuoglu E, Comparision of three back-propagation training algorithms for two case studies, Indian Journal of Engineering and Material Sciences, 12, (2005), 434-442.

24 Kung GTC, Hsiao ECL, Schuster M, Juang $\mathbf{C H}$, A neural network approach to estimating deflection of diaphragm walls caused by excavation in clays, Computers and Geotechnics, 34(5), (2007), 385-396, DOI 10.1016/j.compgeo.2007.05.007 
25 Kuo YL, Jaksa MB, Lyamin AV, Kaggwa WS, ANN-based model for predicting the bearing capacity of strip footing on multi-layered cohesive soil, Computers and Geotechnics, 36(3), (2009), 503-516, DOI 10.1016/j.compgeo.2008.07.002

26 Kurian NP, Shell Foundations: Geometry, Analysis, Design and Construction, Alpha Science Intl Ltd, 2006.

27 Laman M, Uncuoglu E, Prediction of the moment capacity of short pier foundations in clay using the neural networks, Kuwait Journal Science and Engineering, 36(1B), (2009), 1-20.

28 Maier HR, Dandy GC, Applications of artificial neural networks to forecasting of surface water quality variables: issues, applications and challenges, Springer Netherlands, 2000.

29 Mamak M, Seckin G, Cobaner M, Kisi O, Bridge afflux analysis through arched bridge constrictions using artificial intelligence methods, Civil Engineering and Environmental Systems, 26(3), (2009), 279-293, DOI 10.1080/10286600802151804

30 Nawari NO, Liang R, Nusairat J, Artificial intelligence techniques for the design and analysis of deep foundations, Electronic Journal of Geotechnical Engineering, (1999).

31 Padmini D, Ilamparuthi K, Sudheer KP, Ultimate bearing capacity prediction of shallow foundations on cohesionless soils using neurofuzzy models, Computers and Geotechnics, 35(1), (2008), 33-46, DOI 10.1016/j.compgeo.2007.03.001

32 Rumelhart DE, McClelland JL, Parallel recognition in modern computers, MIT Press / Bradford Books, 1986.

33 Samui P, Application of statistical learning algorithms to ultimate bearing capacity of shallow foundation on cohesionless soil, International Journal for Numerical and Analytical Methods in Geomechanics, 36(1), (2012), 100 110, DOI 10.1002/nag.997

34 Shahin MA, Jaksa MB, Maier HR, Artificial neural network applications in geotechnical engineering, Australian Geomechanics, 36(1), (2001), 49-62.

35 Shahin MA, Maier HR, Jaksa MB, Data Division for Developing Neural Networks Applied to Geotechnical Engineering, Journal of Computing in Civil Engineering, 18(2), (2004), 105-114, DOI 10.1061/(ASCE)08873801(2004)18:2(105)

36 Sudheer KP, Knowledge Extraction from Trained Neural Network River Flow Models, Journal of Hydrologic Engineering, 10(4), (2005), 264-269, DOI 10.1061/(ASCE)1084-0699(2005)10:4(264)

37 Tani K, Craig WH, Bearing Capacity of Circular Foundations on Soft Clay of Strength Increasing with Depth., Soils and Foundations, 35(4), (1995), 2135, DOI 10.3208/sandf.35.4_21

38 Thirumalaiah K, Deo M, River Stage Forecasting Using Artificial Neural Networks, Journal of Hydrologic Engineering, 3(1), (1998), 26-32, DOI 10.1061/(ASCE)1084-0699(1998)3:1(26)

39 Wang J, Rahman MS, A neural network model for liquefaction-induced horizontal ground displacement, Soil Dynamics and Earthquake Engineering, 18(8), (1999), 555-568, DOI 10.1016/S0267-7261(99)00027-5

40 Watson PG, Randolph MF, Vertical capacity of caisson foundations in calcareous sediments, 7th International Offshore and Polar Engineering Conference, ISOPE-97, In:; Honolulu, Hawaii, USA, 1997.

41 Zurada JM, Introduction to Artificial Neural Systems, West Publishing Company, 1992. 